\title{
The impact of using different doses of progesterone on memory performance
}

\author{
Roozbehi $\mathrm{A}^{3}$, Sharafi $\mathrm{MT}^{3}$, Karimi $\mathrm{F}^{4}$, Kamali $\mathrm{AM}^{1,2}$ \\ Department of Neuroscience, School of Advanced Medical Sciences and Technologies, Shiraz University \\ of Medical Sciences, Shiraz, Iran. ali.kamali321@gmail.com
}

\section{ABSTRACT}

OBJECTIVE: Progesterone is a sex hormone and its receptors are expressed throughout the hippocampus. This study was aimed at evaluating the effects of different doses of progesterone on memory.

METHODS: Male rats were arbitrarily assigned to nine groups, namely Group I: control, Group II: control-cannula, Group III received $0.5 \mu \mathrm{l}$ of saline by cannula, Groups IV , V, VI, VII and VIII received progesterone in doses of $0.5,1,1.5,2$, and $3 \mu \mathrm{g} / 0.5 \mu \mathrm{l}$ by cannula, respectively. Group IX received $0.5 \mu \mathrm{l}$ almond oil by cannula. Memory performance was tested in form of passive avoidance task.

RESULTS: Our results indicated that progesterone at doses of 1.5 and $2 \mu \mathrm{g}(\mathrm{p}<0.05)$ significantly increased the memory performance while at a dose of $3 \mu \mathrm{g}(\mathrm{p}<0.05)$, it significantly decreased memory as compared to the control group. CONCLUSION: The current study revealed that the influence of progesterone on memory is related to its dose (Fig. 1, Ref. 25). Text in PDF www.elis.sk.

KEY WORDS: progesterone, hippocampus, passive avoidance task, memory.

\section{Introduction}

Different compounds can have effects on memory formation. Sex hormones such as estrogen and progesterone can improve the cognitive processes. Progesterone is a female sex hormone which is also found in males (1). In men, progesterone is used for prostate hyperplasia (2). Moreover, previous studies have revealed that progesterone can affect sleep and erectile function (3, 4). This hormone can play a role in different stages of memory formation. It is well known that there is a connection between estrogen and memory; however, the role of progesterone in cognition is controversial (1). As a neurosteroid, progesterone has protective effects on the central and peripheral nervous systems; it can also reduce neuronal destruction and accelerate neuronal regeneration (5). Decreased progesterone levels with aging increase the risk of neurodegenerative diseases such as Alzheimer's disease (6). Investigations have shown that progesterone recep-

\begin{tabular}{l}
\hline${ }^{1}$ Department of Neuroscience, School of Advanced Medical Sciences and \\
Technologies, Shiraz University of Medical Sciences, Shiraz, Iran, ${ }^{2}$ Neu- \\
roscience Laboratory (Brain, Cognition and Behavior), Department of \\
Neuroscience, School of Advanced Medical Sciences and Technologies, \\
Shiraz University of Medical Sciences, Shiraz, Iran, ${ }^{3}$ Cellular and Molecu- \\
lar Research Center, Yasuj University of Medical Sciences, Yasuj, Iran, \\
and ${ }^{4}$ Department of Anatomy, School of Medicine, Shiraz University of \\
Medical Sciences, Shiraz, Iran
\end{tabular}

Address for correspondence: A.M. Kamali, Department of Neuroscience, School of Advanced Medical Sciences and Technologies, Shiraz University of Medical Sciences, P.O. Box 1433671348 Shiraz, Iran. Phone: +98.71.32340032, Fax: +98.71.32340033

Acknowledgements: This work was financially supported by Yasuj University of Medical Sciences, Yasuj, Iran. This article was a part of the thesis written by Mohammad Taghi Sharafi, MSc. tors are also present in the cerebral cortex and subcortical regions (7). In addition, it seems that progesterone plays an important role in the cognitive function in specific areas of brain such as hippocampus and forebrain. These regions are associated with memory (8). The hippocampus is a main structure in human and animal brains. It is divided into three parts, namely CA1, CA2, and CA3 (9). The hippocampus plays crucial roles in short-term and long-term types of memory (10). Previous studies have revealed that progesterone administration prevents neurodegeneration in the hippocampus (11). This hormone can protect the central nervous system under harmful conditions including oxidative stress, stroke, and neuronal damage (12). The present study aims to examine the hypothesis that intra-hippocampal injection of progesterone at different doses can improve the memory performance in adult male rats.

\section{Materials and methods}

\section{Animals}

In this study, 90 three-month old adult male Sprague-Dawley (250-300 g) rats were acquired from the laboratory animal center of the University. The Ethics Committee of the University approved the animal experiment and entire handling was done under the standard rules of the Animal Ethics Committee. Each group included 10 rats which were retained under standard conditions, room temperature $\left(22-24{ }^{\circ} \mathrm{C}\right)$, and a $12 / 12 \mathrm{~h}$ light/dark plan and had free access to water and food. Group I: control, group II: control-cannula, and group III received $0.5 \mu \mathrm{l}$ of saline by cannula; groups IV , V, VI, VII and VIII received progesterone in doses $0.5,1,1.5,2$, and $3 \mu \mathrm{g} / 0.5 \mu \mathrm{l}$ by cannula, respectively. Group IX received $0.5 \mu 1$ almond oil by cannula. 

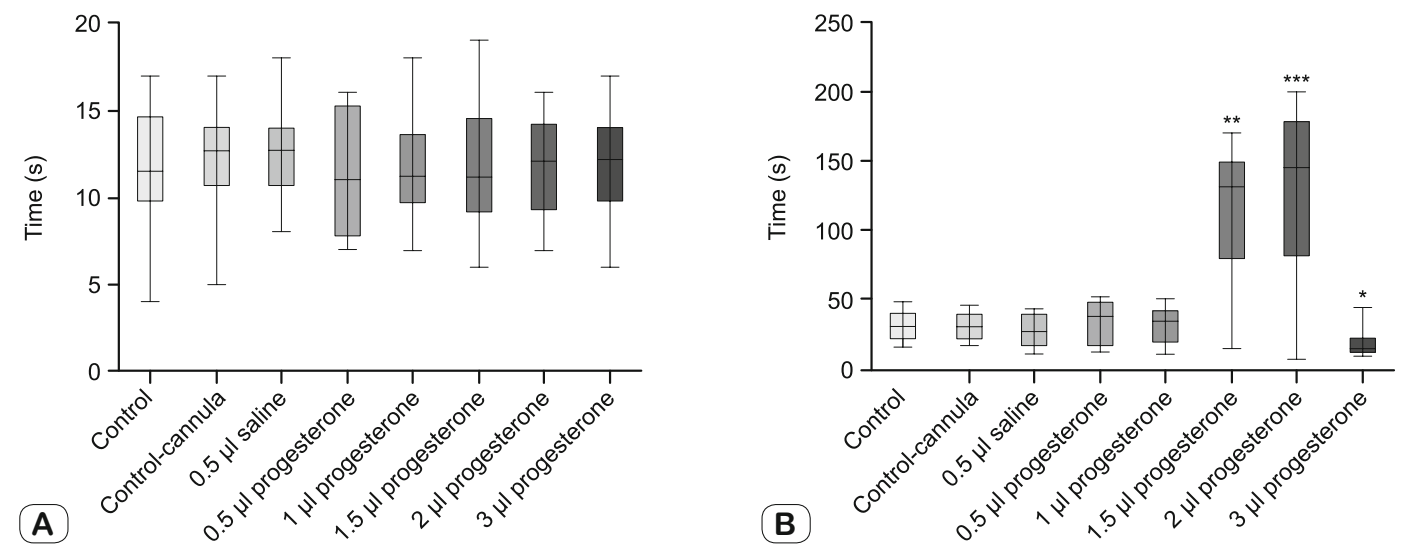

Fig. 1. Results of the passive avoidance response test. (A) The box plots show the groups comparisons regarding the mean of latency time in passive avoidance task before the training session. (B) The box plots show the groups comparisons regarding the mean of latency time in passive avoidance task after the training session. * $p<0.05$ (progesterone $(3 \mu \mathrm{g})$ vs control), $* * p<0.01$ (progesterone $(1.5 \mu \mathrm{g})$ vs control) and *** $\mathrm{p}<\mathbf{0 . 0 0 1}$ (progesterone $(2 \mu \mathrm{g})$ vs control).

\section{Surgical procedures}

Rats were anesthetized with KX solution (100 and $10 \mathrm{mg} / \mathrm{kg}$ BW of ketamine and xylazine, respectively) which was administered intraperitoneally for surgical procedures. Two cannulae were located in site of injection according to the 6th edition of the Paxinos Atlas (13). Stereotaxic coordinates for the left CA1 area of the hippocampus were AP: $-3.8 \mathrm{~mm}$ from bregma, ML: \pm 2.2 from the sagittal suture and DV: $-2.4 \mathrm{~mm}$ from the dura mater. The cannula was protected in place with dental cement and two screws. All rats were permitted 7 days to recover from surgery. For drug injection, a 27-gauge injection needle which was connected to a polyethylene tube fixed to a $10 \mu \mathrm{l}$ Hamilton syringe was used. The solutions were injected in course of $60 \mathrm{~s}$.

\section{Passive avoidance test}

Passive avoidance test was designed to assess long-term memory in experimental animals. All rats were familiarized with the shuttle box in a soundproof room. They were adapted in a conditioning room for $20 \mathrm{~min}$ before every treatment. The shuttle box (passive avoidance apparatus) consisted of two compartments, a white and a black room ( $\left.25 \times 25 \times 25 \mathrm{~cm}^{3}\right)$ divided by a sliding door (14). The electric foot-shock is delivered through the floor composed of metal grids designed for delivering electric foot-shock at $0.5 \mathrm{~mA}$ for $3 \mathrm{~s}$. For the habituation session (Day 1), the rats were located into the shuttle box and the sliding door was opened to permit the rats to freely explore the white and black rooms of the shuttle box for $3 \mathrm{~min}$. In the training session (Day 2), the assigned rats were located into the white room but the sliding door was closed. After 30 seconds from start of training session, the sliding door was opened and latency to enter the dark box was recorded. When the rat passed into the dark room, the sliding door was closed and the subject rat received an unavoidable continuous electric foot-shock at $0.5 \mathrm{~mA}$ for $3 \mathrm{~s}$. Rats were removed after receiving the electric shock. Control rats were returned to their individual home-cages. The animals in the experimental groups were injected after the training session. In the retention session (Day 3 ), after $48 \mathrm{~h}$ had passed, the assigned rats were located into the white room. After 30 seconds, the sliding door was opened and latency to enter the dark box was noted. At this stage, the cut-off latency was put at $300 \mathrm{~s}$ to enter the dark box. The shuttle box was washed with $70 \%$ ethanol and wiped dry with a paper towel between each conditioning test.

\section{Statistical analysis}

The data were analyzed using one-way ANOVA with posthoc Tukey's test. $\mathrm{p} \leq 0.05$ was considered statistically significant.

\section{Results}

Evaluation of memory before the training session

The results showed that before the training session, there was no significant difference between the groups in the latency in entering the dark box $(\mathrm{p}<0.05)$ (Fig. 1A).

\section{Evaluation of memory after intra hippocampal administration of progesterone}

After 48 hours of training, progesterone at doses of 1.5 and $2 \mu \mathrm{g}(\mathrm{p}<0.05)$ significantly increased the latency in entering the dark box as compared to the control group, indicating that progesterone improved the long-term memory process. Furthermore, progesterone at the dose of $3 \mu \mathrm{g}(\mathrm{p}<0.05)$ significantly decreased the latency in entering the dark box as compared to the control group (Fig. 1B). This result suggests that progesterone can disrupt memory when administered in high doses (Fig. 1B).

\section{Discussion}

According to the present results, no pre-training significant difference in entering the black box was observed between the groups. These findings showed that all the rats were studied under similar conditions. In the testing phase, there was no significant difference between the saline and control groups in terms of delay in entering the dark box. In other words cannulation, anesthesia, and saline in- 
fusion had no effect on long-term memory. The results also showed that the long-term memory was improved in the groups administered with 1.5 and $2 \mathrm{~mL}$ of progesterone in the same vein. Some studies have shown that progesterone affects the neurons involved in learning and memory $(15,16)$. Administration of progesterone in postmenopausal women improved memory performance in several behavioral tasks (17). Also, administration of allopregnanolone enhanced long-term and spatial working memory (18). Studies have revealed that different forms of memory require the hippocampus to be consolidated (19). Other studies have demonstrated that administration of progesterone can prevent hippocampal cell destruction. It has also been revealed that progesterone has antioxidant effects in the hippocampus (11). Furthermore, progesterone facilitates synaptic currents in the hippocampal CA1 region, reduces toxic effects on the nervous system, and can delay the aging process (20). It has been confirmed that the gonadal steroid hormones can extensively regulate the memory processes and the number of dendritic spines ofCA1 pyramidal neurons decreased by $50 \%$ after gonadectomy (21). Progesterone regulates the hippocampal GABA receptors which play a role in memory functions (22). Another possible mechanism could be clarified by the research by Lewis et al (2008) who reported that progesterone receptors are expressed in all subregions of the hippocampus (23). Neuroprotective effects of progesterone and its influence on synaptic plasticity have been confirmed. This hormone activates the intracellular pathways such as MAPK/ERK, thus contributing to the neuroprotection and plasticity (15). On the other hand, our results indicated that progesterone at a dose of $3 \mu \mathrm{g}$ decreased memory as compared to the control group. This finding is in line with previous studies reporting that progesterone at high doses can have a damaging effect on memory (24) and consistent with the results of the present study. Moreover, ElBakri et al (2004) indicated that low-dose estrogen usage showed better learning and memory than high-dose estradiol administration. Treatment with high doses of female sex hormones can decrease the dendritic spine and synapse in CA1 hippocampus (25). The current study indicated that doses of 1.5 and $2 \mu \mathrm{g}$ of progesterone were effectively able to increase memory in a passive avoidance task.

\section{References}

1. Barros L, Tufik S, Andersen M. The role of progesterone in memory: an overview of three decades. Neuroscience \& Biobehavioral Reviews 2015; 49: 193-204.

2. Kaore SN, Langade DK, Yadav VK, Sharma P, Thawani VR, Sharma R. Novel actions of progesterone: what we know today and what will be the scenario in the future? J Pharm Pharmacol 2012; 64: 1040-1062.

3. Andersen ML, Tufik S. Effects of progesterone blockade over cocaineinduced genital reflexes of paradoxical sleep-deprived male rats. Horm Behav 2005; 47: 477-484.

4. Andersen ML, Tufik S. Does male sexual behavior require progesterone? Brain Res Rev 2006; 51: 136-143.

5. Djebaili M, Hoffman S, Stein D. Allopregnanolone and progesterone decrease cell death and cognitive deficits after a contusion of the rat pre-frontal cortex. Neuroscience 2004; 123: 349-359.

6. Carroll JC, Rosario ER, Chang L, Stanczyk FZ, Oddo S, LaFerla FM et al. Progesterone and estrogen regulate Alzheimer-like neuropathology in female 3xTg-AD mice. J Neurosci 2007; 27: 13357-13365.
7. Schumacher M, , Mattern C, Ghoumari A, Oudinet JP, Liere P, Labombarda $\mathbf{F}$ et al. Revisiting the roles of progesterone and allopregnanolone in the nervous system: resurgence of the progesterone receptors. Progr Neurobiol 2014; 113: 6-39.

8. McKuen B, Alves B. Estrogen action in the central nervous system. Endocrin Rev 1999; 20: 279-307.

9. Miki T, Satriotomo I, Li HP, Matsumoto Y, Gu H, Yokoyama T et al. Application of the physical disector to the central nervous system: estimation of the total number of neurons in subdivisions of the rat hippocampus. Anat Sci Internat 2005; 80: 153-162.

10. Ruediger S, Spirig D, Donato F. Goal-oriented searching mediated by ventral hippocampus early in trial-and-error learning. Nature Neurosci 2012; 15: 1563-1571.

11. He L, Yang H, Zhai LD, Shao H, Li YS et al. A preliminary study on progesterone antioxidation in promoting learning and memory of young ovariectomized mice. Arch Med Sci 2011; 7: 397-404.

12. Singh M, Su C. Progesterone and neuroprotection. Hormones and behavior 2013; 63: 284-290.

13. Paxinos G, Watson C. The rat brain in stereotaxic coordinates. San Diego: Academic Press, 2006.

14. Takeo I, Kumiko T, Tadashi I, Akira I, Satoko T, Yukihiro O. A novel atypical antipsychotic drug, reverses MK-801-inducedimpairment of learning and memory in the rat passive-avoidance test. Eur J Pharmacol 2007; 572: $160-170$.

15. Baudry M, Bi X, Aguirre C. Progesterone-estrogen interactions in synaptic plasticity and neuroprotection. Neurosci 2013; 239: 280-294.

16. Choi JM, Romeo RD, Brake WG, Bethea CL, Rosenwaks Z, McEwen BS et al. Estradiol increases pre-and post-synaptic proteins in the CA1 region of the hippocampus in female rhesus macaques (Macaca mulatta). Endocrinology 2003; 144: 4734-4738.

17. Natale V, Albertazzi P, Zini M, Di Micco R. Exploration of cyclical changesin memory and mood in postmenopausal women taking sequential combinedoestrogen and progestogen preparations. BJOG 2001; 108: 286-290.

18. Frye CA, Sturgis JD. Neurosteroids affect spatial/reference, working, andlong-term memory of female rats. Neurobiol Learning Memory 1995; 64: 83-96.

19. Baulieu EE. Neurosteroids: of the nervous system, by the nervous system, for the nervous system. Rec Progr Hormone Res 1996; 52: 1-32.

20. Tanabe F, Miyasaka N, Kubota T, Aso T et al. Estrogen and progesterone improve scopolamine-induced impairment of spatial memory. J Med Dent Sci 2004; 51: 89-98.

21. Frye CA, Duffy CK, Walf AA., Estrogens and progestins enhance spatial learning of intact and ovariectomized rats in the object placement task. Neurobiol Learning Memory 2007; 88: 208-216.

22. Fontani, G, Corradeschi F, Felici A, Alfatti F, Migliorini S, Lodi L et al. Cognitive and physiological effects of Omega-3 polyunsaturated fatty acid supplementation in healthy subjects. Eur J Clin Invest 2005; 35: 691-699.

23. Lewis MC, Orr PT, Frick KM. Differential effects of acute progesterone administration on spatial and object memory in middle-aged and aged female C57BL/6 mice. Horm Behav 2008; 54: 455-462.

24. Freeman EW, Weinstock L, Rickels K, Sondheimer SJ, Coutifaris C. Aplacebo-controlled study of effects of oral progesterone on performance andmood. Br J Clin Pharmacol 1992; 33: 293-298.

25. El-Bakri N, Islam A, Zhu S, Elhassan A, Mohammed A, Winblad B et al. Effects of estrogen and progesterone treatment on rat hippocampal NMDA receptors: Relationship to Morris water maze performance. J Cell Mol Med 2004; 8: 537-544.

Received February 26, 2017. Accepted March 10, 2017. 